\title{
Pharmacokinetic evaluation of Chalcone derivatives with antimalarial activity in New Zealand White Rabbits
}

\author{
Shweta Sinha ${ }^{1}$, Ajay Prakash², Bikash Medhi ${ }^{2}$, Alka Sehgal ${ }^{3}$, Daniela I. Batovska ${ }^{4}$ and Rakesh Sehgal ${ }^{1 *}$ (D)
}

\begin{abstract}
Objective: Malaria is a major global health concern with the urgent need for new treatment alternatives due to the alarming increase of drug-resistant Plasmodium strains. Chalcones and its derivatives are important pharmacophores showing antimalarial activity. Determination of the pharmacokinetic variables at the preliminary step of drug development for any drug candidates is an essential component of in vivo antimalarial efficacy tests. Substandard pharmacokinetic variables are often responsible for insufficient therapeutic effect. Therefore, three chalcone derivatives, 1, 2, and 3, having antimalarial potency were studied further for potential therapeutic efficacy.

Results: In vivo pharmacokinetic studies of these three derivatives were performed on New Zealand White rabbits. The three derivatives were administered intra-peritoneally or orally at effective dose concentration and blood samples at different time points were collected. The determination of drug concentration was done through reverse phase-high performance liquid chromatography. The peak plasma concentration of derivative 1, 2, and 3 were $1.96 \pm 0.46 \mu \mathrm{g} / \mathrm{mL}$ (intraperitoneal route), $69.89 \pm 5.49 \mu \mathrm{g} / \mathrm{mL}$ (oral route), and $3.74 \pm 1.64 \mu \mathrm{g} / \mathrm{mL}$ (oral route). The results indicate a very low bioavailability of these derivatives. The present study gives a benchmark to advance the investigation of more derivatives in order to revamp the pharmacokinetic variables while maintaining both potency and metabolic constancy.
\end{abstract}

Keywords: Malaria, Chalcones, RP-HPLC, Bioavailability

\section{Introduction}

Malaria caused due to $P$. falciparum, the most virulent species, is a remarkable reason for the morbidity and mortality all over the globe [1]. Artemisinin-combination therapy is the most recommended therapy till now for $P$. falciparum malaria. However, the appearance of artemisinin resistant strains of $P$. falciparum in the various part of the greater Mekong subregion has raised major concern because of the lack of appropriate alternative therapies [2]. This shows the necessity for the

\footnotetext{
*Correspondence: sehgalpgi@gmail.com

${ }^{1}$ Department of Medical Parasitology, Post Graduate Institute of Medical

Education and Research, Chandigarh 160012, India

Full list of author information is available at the end of the article
}

development of a unique generation of curatives that can target the threats of the malaria elimination agenda [3]. Malaria chemotherapy has a strong historical link to plant and natural products, in this context chalcones an important pharmacophore has been explored extensively from past decades for antimalarial activity [4].

Chalcones, or 1,3-diaryl-2-propen-1-ones, belongs to the flavonoid family and chemically they consist of openchain flavonoids in which the two aromatic rings are joined by a three-carbon a, b-unsaturated carbonyl system. The radical dousing ability due to the presence of the phenolic groups in numerous chalcones has heightened the attentiveness in the utilization of these compounds or their derivatives in the form of food preservatives or drugs [5]. Primeval therapeutic application of chalcones

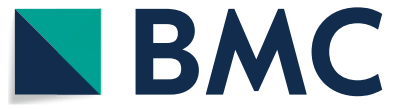

(c) The Author(s) 2021. This article is licensed under a Creative Commons Attribution 4.0 International License, which permits use, sharing, adaptation, distribution and reproduction in any medium or format, as long as you give appropriate credit to the original author(s) and the source, provide a link to the Creative Commons licence, and indicate if changes were made. The images or other third party material in this article are included in the article's Creative Commons licence, unless indicated otherwise in a credit line to the material. If material is not included in the article's Creative Commons licence and your intended use is not permitted by statutory regulation or exceeds the permitted use, you will need to obtain permission directly from the copyright holder. To view a copy of this licence, visit http://creativeco mmons.org/licenses/by/4.0/. The Creative Commons Public Domain Dedication waiver (http://creativecommons.org/publicdomain/ zero/1.0/) applies to the data made available in this article, unless otherwise stated in a credit line to the data. 
is known to be linked with the utilization of several-yearold herbs and plants for the remedy of distinct medical ailments [6]. Chalcones, either in form of natural or synthetic, are well known to illustrate an extensive spectrum of biological activities, including antimalarial [7], antiinflammatory [8], cytotoxic $[9,10]$, anticancer properties [11, 12], modification of P-glycoprotein-mediated multidrug resistance [13], and antioxidant [14]. Due to simple chemical structure, accessibility, and numerous methods of cyclization, this specific class of compounds has meant as central in the quest for lead molecules having therapeutic implication. With the evident of therapeutic application, our groups have synthesized a series of new derivatives of chalcones which were screened for antimalarial activity in vitro culture system $[15,16]$. However, because of poor pharmacokinetic variables such as short half-life, low bioavailability, fast metabolism, and accelerated clearance ensuing in a short period of action, restricts the drug from being deployed for the actual therapeutic effect [17]. Additionally, in the vast majority of the cases, antimicrobial therapeutics which exhibit immense antimicrobial activity under in vitro, fails to reveal their therapeutic activity in the experimental infection models [18]. For this cause, it is critical to appraise the pharmacokinetic variables of potential lead compounds at the preliminary stage of drug development [17]. Considering these facts, the three potent chalcone derivatives having antimalarial activity were studied further for pharmacokinetic evaluation.

\section{Main text}

\section{Materials and methods}

\section{Chemical and reagents}

Pure form of Chalcone was bought from Sigma Aldrich and was utilized as in same form considering as a reference standard. The methanol and water used in the experiments were of HPLC analytical grade. The three chalcone derivatives namely,

(E)-1-(2,5-Dimethoxyphenyl)-3-(4-methoxyphenyl) prop-2-en-1-one, (1);

(E)-(3,4,5-Trimethoxyphenyl)-3-(4-methoxyphenyl) prop-2-en-1-one, (2); and.

(E)-1-(3,4,5-Trimethoxyphenyl)-3-(3,4-dimethoxyphenyl)prop-2-en-1-one,(3),were synthesized as delineated formerly by our group [15] and NMR characterization of these derivatives with their molecular structure are shown in Fig. 1a-c and detailed outline of NMR spectral reading is given in Additional file 1.

\section{Pharmacokinetic studies}

The ten healthy adult New Zealand White rabbits weighing between $1.75-2.75 \mathrm{~kg}$ of either sex were procured from the institute Advanced Facility for Small Animal
Research, PGIMER Chandigarh, after approval from the Institutional Animal Ethics Committee Ref. No. 69/ IAEC/418 as per the Committee for the Purpose of Control and Supervision of Experiments on Animals (CPCSEA) guidelines. The animals were housed in polypropylene cages under standard laboratory conditions at controlled temperature $\left(25 \pm{ }^{\circ} \mathrm{C}\right)$ and 12-h light/dark cycles until the end of the experimental period. Animals were given free access to diet and water in a room and were fasten for at least $12 \mathrm{~h}$ prior to experiment. To achieve meaningful statistical results, we used a minimally sufficient number of animals in all cases. A fifteen-days washout period was carried out, which allows animals to completely recover and clear off the administered derivatives.

A total of ten healthy adult New Zealand White rabbits were divided into three groups; (i) derivative 1 treated group, (ii) derivative 2 treated group, and (iii) derivative 3 treated group. The whole experiment was performed in two batches with each batches containing $n=3$ animals per group. The second batch with same groups were repeated after giving fifteen-days washout period which helps animals to recover and clear off previous administered derivatives. The three chalcone derivatives were administered at effective dose concentration [dose extrapolated from in vitro study, [15] as per OECD GLP compliance. A single dose of each chalcone derivatives 1,2 \& 3 (suspended in $0.5 \%$ carboxymethyl cellulose) were administered to each animal in the early morning at 7:00 am, which was noted as $0 \mathrm{~h}$ and then blood samples $(1 \mathrm{~mL})$ of animals were collected at specific time intervals of $0,0.25 \mathrm{~h}, 0.5 \mathrm{~h}, 1 \mathrm{~h}, 2 \mathrm{~h}, 4 \mathrm{~h}, 6 \mathrm{~h}, 8 \mathrm{~h}, 12 \mathrm{~h}$, $24 \mathrm{~h}, 36 \mathrm{~h}, 48 \mathrm{~h}$ from marginal ear vein in heparin containing vials. These derivatives were either administered orally through orogastric tube or intraperitoneally. All blood samples were collected from the marginal ear vein after topical anaesthesia with $4 \%$ lignocaine solution. No euthanasia procedure was required during the study, and after completion of experiments all animals were kept in rehabilitation centre according to CPCSEA guidelines, in the institute Advanced Facility for Small Animal Research, PGIMER, Chandigarh. Plasma samples for the determination of drug concentration were prepared for RP-HPLC analysis.

\section{Assay procedure}

Preparation of Plasma Sample Rabbit blood samples were accumulated in heparin contained dry evacuated tubes from marginal ear veins of healthy rabbits as per the standard operating procedure. These samples were centrifuged within $1 \mathrm{~h}$ of collection, for segregation of plasma at $1500 \mathrm{rpm}$ for $10 \mathrm{~min}$. The segregated plasma was preserved at $20^{\circ} \mathrm{C}$ till assay. Prior experimental analy- 


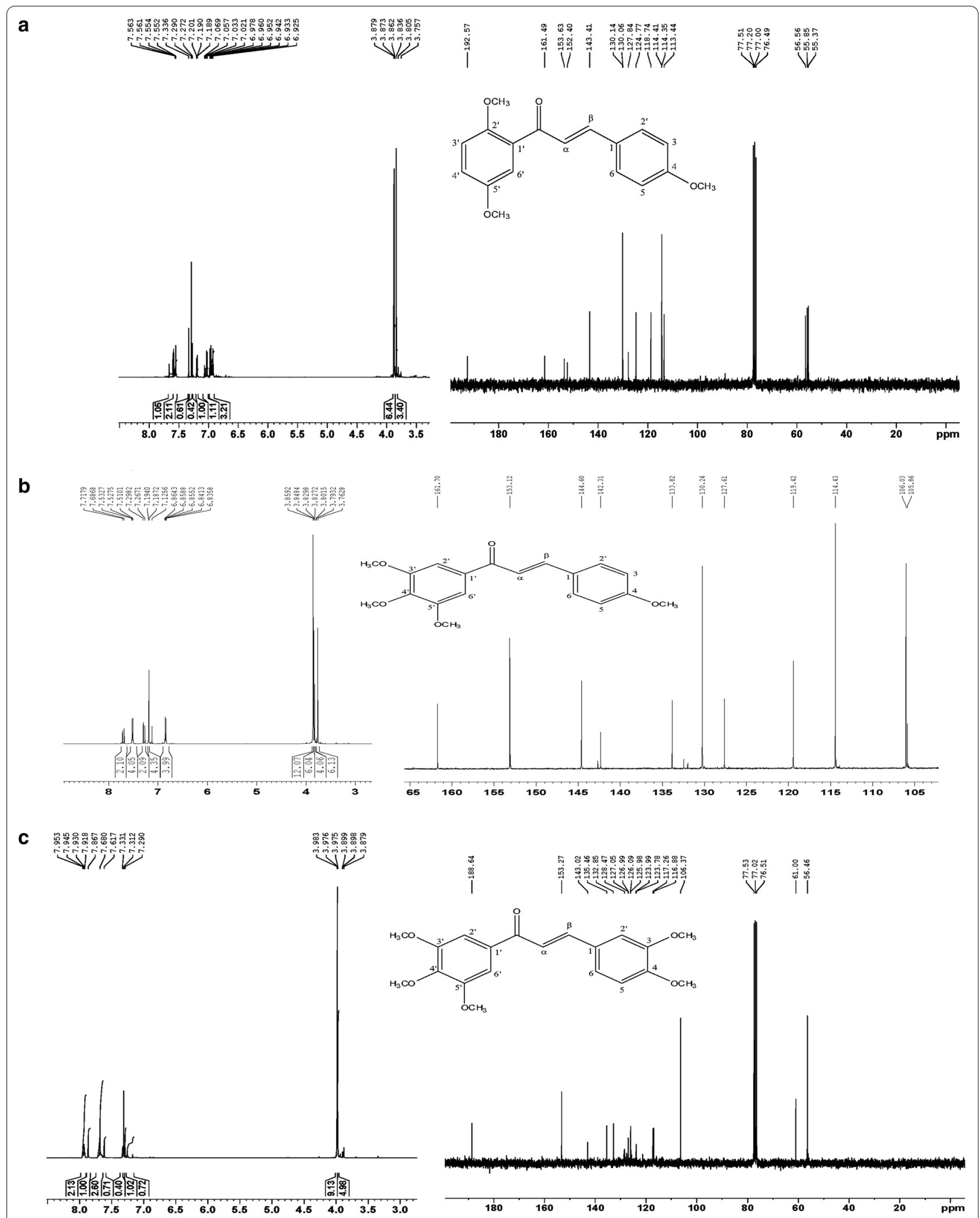

Fig. 1 NMR Spectrum and molecular structure of chalcone derivatives. a NMR spectrum $\left(600 \mathrm{MHz}, \mathrm{CDCl}_{3}\right)$ and molecular structure of compound 1, b NMR spectrum $\left(500 \mathrm{MHz}_{1} \mathrm{CDCl}_{3}\right)$ and molecular structure of compound 2, and $\mathbf{c} \mathrm{NMR}$ spectrum $\left(600 \mathrm{MHz}_{1} \mathrm{CDCl}_{3}\right)$ and molecular structure of compound 3 
sis the deproteinization of the plasma samples was done in the mixture of methanol and water $(90: 10 \mathrm{v} / \mathrm{v})$, then vortexed for at least 10-15 min, after while centrifuged for at least $15 \mathrm{~min}$ at $6000 \mathrm{rpm}$, and finally supernatants were pipette-out in a new vial. The supernatants were then spiked with the measured volume of diluted stock solutions of chalcone making up to final concentrations of $10-100 \mu \mathrm{g} / \mathrm{mL}$. Each sample of $20 \mu \mathrm{L}$ volume was injected through a Rheodyne injector in the instrument and the effluent was observed at $310 \mathrm{~nm}$.

Standard preparation A concentrated $(100 \mu \mathrm{g} / \mathrm{mL})$ stock solution was obtained by solubilizing $10 \mathrm{mg}$ of chalcone in $10 \mathrm{~mL}$ of methanol and then the final volume was added up to $100 \mathrm{~mL}$ with the mobile phase in $100 \mathrm{~mL}$ volumetric flask. The working solution of chalcone was prepared by diluting the stock solution with the mobile phase. The same procedure was followed for plotting the calibration curve for all the three chalcone derivatives, (Additional file 2: Figure S1).

Sample preparation Each sample has been collected from rabbits at a different time interval and plasma was separated and either processed for assay procedure or stored at $-20{ }^{\circ} \mathrm{C}$ in deep freezer till experiment. On the day of the experiment, $100 \mu \mathrm{L}$ of plasma from each vial was transferred to another and mixed with $100 \mu \mathrm{L}$ of acetonitrile (HPLC analytical Grade). Then was kept for $5 \mathrm{~min}$ at room temperature and then centrifuged at $7000 \mathrm{rpm}$ for $10 \mathrm{~min}$. Supernatant was separated and reconstituted with the mobile phase and finally sterile filter with $0.22 \mu \mathrm{m}$ membrane filter before the assay procedure.

Chromatographic conditions Chromatographic separation was achieved as mentioned earlier [19] with slight modification. Briefly, the separation was performed on RP-HPLC at ambient temperature $\left(25{ }^{\circ} \mathrm{C}\right)$ by using a mobile phase consisting of methanol and water in the ratio of $90: 10(\mathrm{v} / \mathrm{v})$ for $10 \mathrm{~min}$. The mobile phase was pumped at a rate of $1.0 \mathrm{~mL} / \mathrm{min}$. The detector wavelength was set at $310 \mathrm{~nm}$.

\section{Pharmacokinetic variables evaluation}

The experimental data and pharmacokinetic variables are shown as the mean \pm standard error mean (SEM). The peak serum concentration $\left(\mathrm{C}_{\max }\right)$ and the time to achieve maximum concentration $\left(t_{\max }\right)$ were retrieved from the observed concentration versus time data profile. The area under the serum concentration-time curve from time zero to the time of final measurable sample $\left(\mathrm{AUC}_{0-48}\right)$ was calculated using the linear trapezoidal method [20].

\section{Results and discussion}

One of the critical steps in the assessment of therapeutic candidates is a relative investigation of pharmacokinetic variables. The timing of compound administration and metabolic stimulation adds to the result of viability testing in vivo [21, 22]. Decreased absolute bioavailability, low distribution, accelerated metabolism as well as elimination, of chalcones, are the primary issues in planning new therapeutics based on their structure. In this study, the peak plasma concentration of derivative 1 was $1.96 \pm 0.46 \mu \mathrm{g} / \mathrm{mL}$ achieved at $0.33 \pm 0.05 \mathrm{~h}$ succeeding a single $3.84 \mathrm{mg} / \mathrm{kg}$ intraperitoneal dose in (Fig. 2a). The mean CL and $\mathrm{V}_{\mathrm{d}}$, of derivatives $\mathbf{1}$ were $0.28 \pm 0.08 \mathrm{~L} / \mathrm{h}$ and $7.31 \pm 0.29 \mathrm{~L}$, respectively. However, the peak plasma concentration of 2 was $69.89 \pm 5.49 \mu \mathrm{g} /$ $\mathrm{mL}$ achieved at $3.4 \pm 0.79 \mathrm{~h}$ following a single $4.85 \mathrm{mg} /$ $\mathrm{kg}$ oral dose, (Fig. 2b) and 3 was $3.74 \pm 1.64 \mu \mathrm{g} / \mathrm{mL}$ achieved at $2.83 \pm 0.87 \mathrm{~h}$ following a single $3.64 \mathrm{mg} / \mathrm{kg}$ oral dose, (Fig. 2c). The mean CL and $V_{d}$, of derivative 2 were $0.15 \pm 0.05 \mathrm{~L} / \mathrm{h}$ and $10.72 \pm 0.66 \mathrm{~L}$, and for 3 was $0.53 \pm 0.10 \mathrm{~L} / \mathrm{h}$ and $9.12 \pm 0.73 \mathrm{~L}$ respectively. Various pharmacokinetic parameters for chalcone derivatives 1 , 2 , and 3 are summarized in (Table 1 ).

The peak concentration of derivative 2 was achieved at $3.84 \mathrm{~h}$ and was remain at constant concentration for $3-4 \mathrm{~h}$. This may result in long half-life of 2 . This finding indicates that $\mathbf{2}$ has a longer half-life compared to other two derivatives $\mathbf{1}$ and $\mathbf{3}$ which is also similar to the attributed reason of chloroquine longer half-life where noticeable amount of the chloroquine was observed for several days in the plasma since after discontinuance of the therapy [23, 24]. Nevertheless, the drug having a longer half-life was associated to considerable tissue cohering, specifically in melanin accommodating tissues, spleen, kidney, liver, lung, and less significantly in the spinal cord and brain. Since drugs bounded to protein are not freely accessible and it cannot be easily spotted in the plasma or serum and cannot be even metabolized [25]. The observed decline in serum concentration, elimination rate constant and clearance rate of derivative 2 might be ascribed to improvement in the binding of derivative 2 to microsomal protein, which results in a lower level of unbounded drug in the serum and therefore a reduction in the above-mentioned variables. Such association gives explanation for the observed surge in the drug half-life as protein association leads to extended half-life of a drug by prolonging its liberation from the tissues [23]. Single oral administration of derivative 2 has comparatively better systemic exposure, compared to other two chalcone derivatives and also has a longer half-life. Moreover, as compared to in vitro concentration [15], compound 1 has three fold, compound 2 has tenfold and compound 3 has 25 fold increased bioavailability. 
a

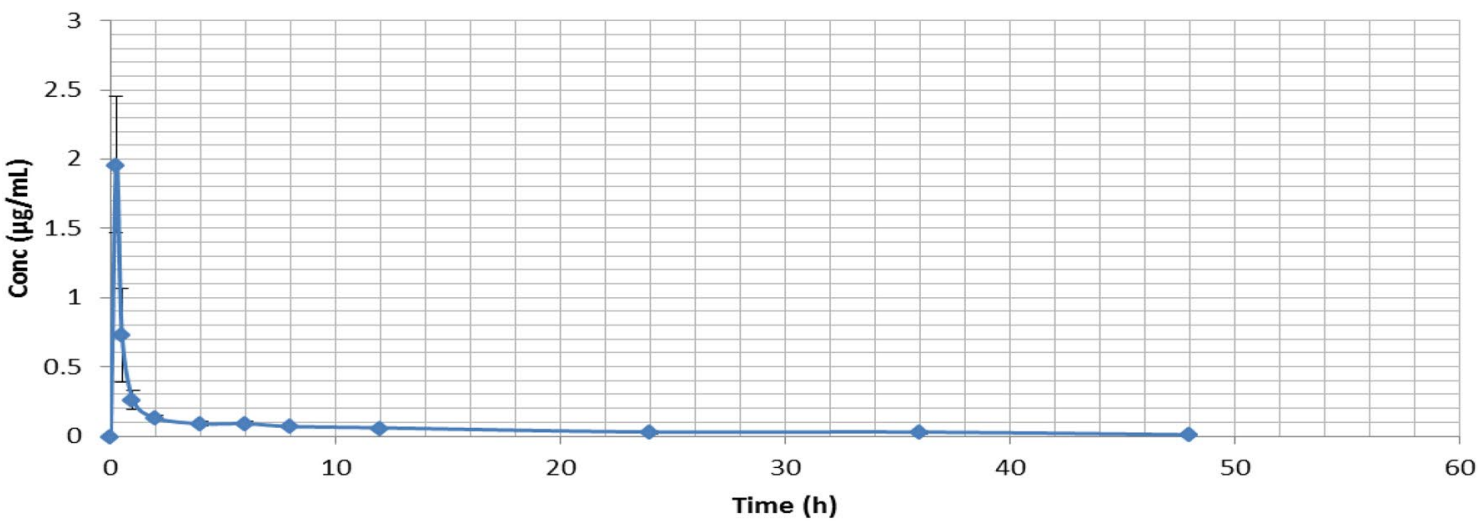

b

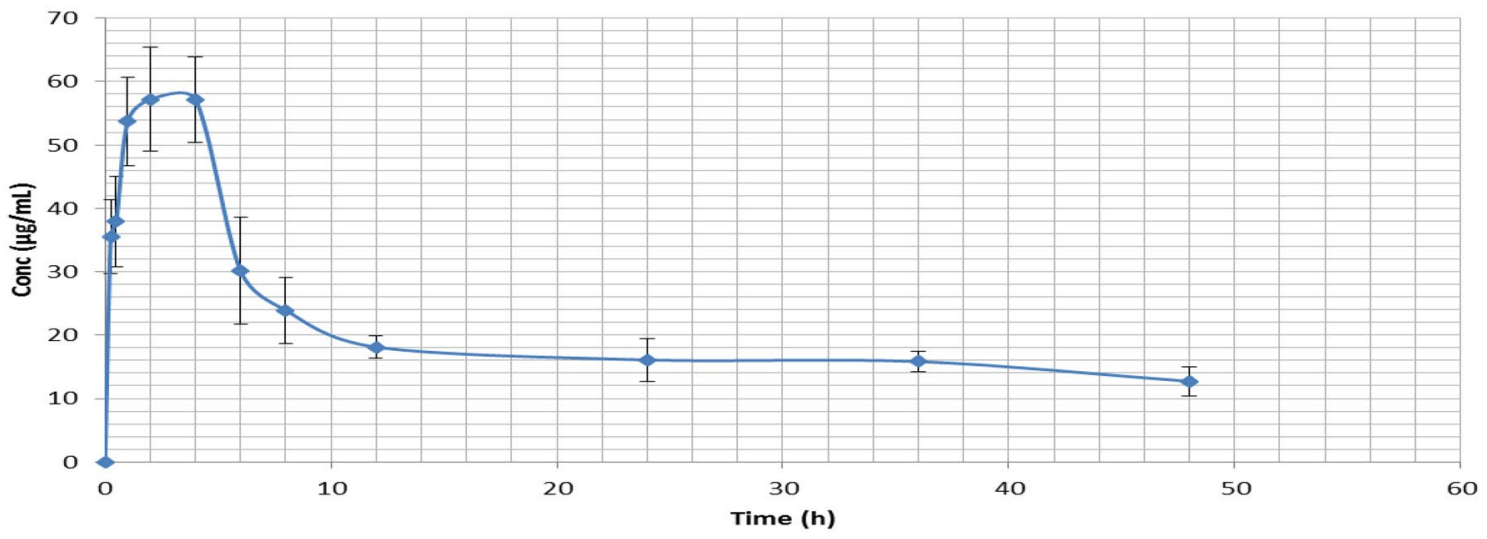

C

3

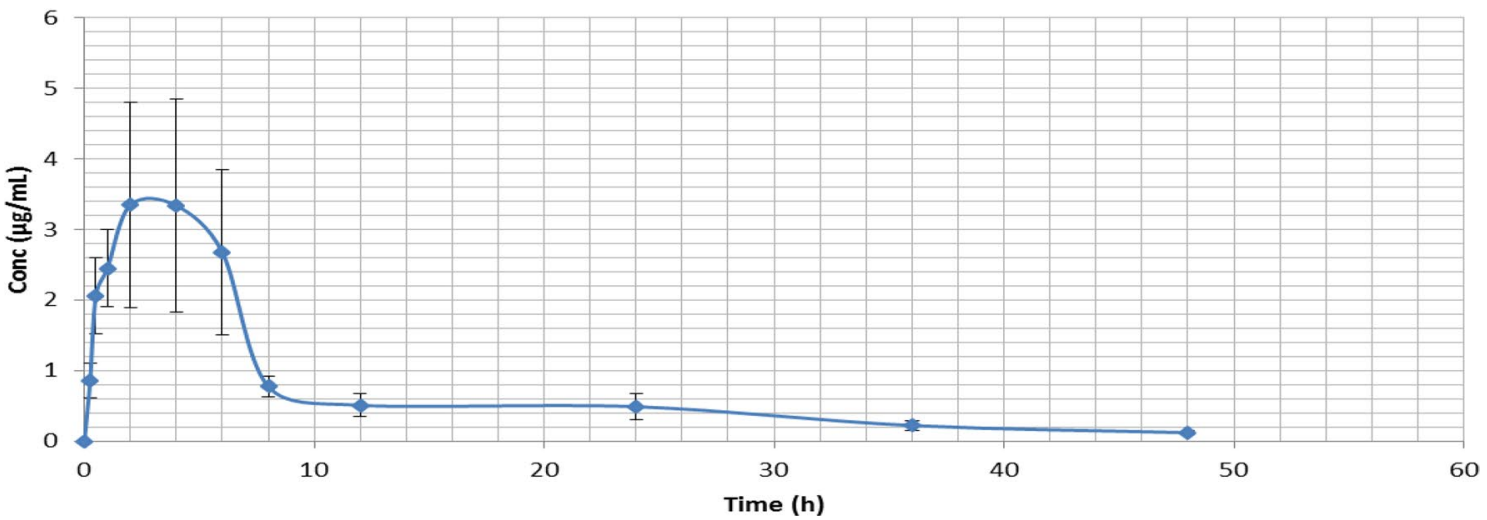

Fig. 2 Plasma concentration-time profile for chalcones derivatives 1,2 and 3. a A single $3.64 \mathrm{mg} / \mathrm{kg}$ intraperitoneal dose administration of derivative 1 in the rabbit $(n=6)$. b A single $4.85 \mathrm{mg} / \mathrm{kg}$ oral dose administration of derivative 2 in the Rabbit $(n=5)$. c A single $3.64 \mathrm{mg} / \mathrm{kg}$ oral dose administration of derivative 3 in the rabbit $(n=6)$. Data represented as (mean $\pm S E M)$

Derivative 3 has poor bioavailability. The metabolism of derivative 3 follows first order kinetics, which explains the steep fall in plasma 3 levels during the elimination phase. Moreover, after IP administration of derivative
1, there was the rapid absorption of the derivative from the rabbit gastrointestinal tract. It was spotted in plasma from the very first blood sampling time (15 min) and quickly reached $T_{\max }(0.33 \mathrm{~h})$ manifesting linear 
Table 1 Pharmacokinetic parameters (mean \pm SEM) after single intraperitoneal/oral dose of three $(1,2 \& 3)$ chalcone derivatives

\begin{tabular}{|c|c|c|c|}
\hline Pharmacokinetic Parameters & $\begin{array}{l}\text { Derivative } 1 \\
\text { (mean } \pm \text { SEM) }\end{array}$ & $\begin{array}{l}\text { Derivative } 2 \\
\text { (mean } \pm \text { SEM) }\end{array}$ & $\begin{array}{l}\text { Derivative } 3 \\
\text { (mean } \pm \text { SEM) }\end{array}$ \\
\hline Administered Dose (mg/1.5 kg Rabbits) & 5.46 & 7.28 & 5.46 \\
\hline Administration Route & Intraperitoneal & Oral & Oral \\
\hline$C_{0}(\mu \mathrm{g} / \mathrm{mL})$ & $0.966 \pm 0.025$ & $0.986 \pm 0.004$ & $0.944 \pm 0.007$ \\
\hline$C_{\max }(\mu \mathrm{g} / \mathrm{mL})$ & $1.96 \pm 0.46$ & $69.89 \pm 5.49$ & $3.74 \pm 1.64$ \\
\hline$t_{\max }(h)$ & $0.33 \pm 0.05$ & $3.4 \pm 0.79$ & $2.83 \pm 0.87$ \\
\hline$t_{1 / 2}(h)$ & $12.60 \pm 2.09$ & $93.32 \pm 32.59$ & $13.30 \pm 1.67$ \\
\hline$A \cup C_{0-48}(\mu \mathrm{g} \cdot \mathrm{h} / \mathrm{mL})$ & $2.94 \pm 0.83$ & $3755.16 \pm 738.71$ & $14.16 \pm 3.78$ \\
\hline $\mathrm{K}_{\mathrm{e}}$ & $-0.035 \pm 0.026$ & $-0.013 \pm 0.004$ & $-0.056 \pm 0.007$ \\
\hline $\mathrm{CL}(\mathrm{mL} / \mathrm{min})$ & $0.28 \pm 0.08$ & $0.15 \pm 0.05$ & $0.53 \pm 0.10$ \\
\hline$V_{d}(L)$ & $7.31 \pm 0.29$ & $10.72 \pm 0.66$ & $9.12 \pm 0.73$ \\
\hline
\end{tabular}

$C_{0}$ Concentration of administrated drug at time zero, $C_{\max }$ Peak plasma concentration, $t_{\max }$ time to reach the peak plasma concentration, $t_{1 / 2}$ elimination half-life, $A U C$ Area under the total plasma concentration-time curve, $K_{e}$ Elimination rate constant, $C L$ Plasma clearance, $V_{d}$ Volume of distribution

dynamics. Overall, the pharmacokinetic study indicates very low bioavailability of derivative $\mathbf{1}$ and $\mathbf{3}$ compared to 2 . This result is consistent to the previous published literature, in which the pharmacokinetic study carried out in Sprague-Dawley rats demonstrates exceptionally poor oral bioavailability of chalcones which could be the explanation behind its decrease antimalarial activity, to rule out parasitemia (100\%) in animal models [22, 26, 27]. Moreover, drug efflux transporters of the ATP binding cassette $(A B C)$ family of proteins display a major part in the regulation of the pharmacokinetic and pharmacodynamic properties of drugs and intriguingly, chalcones are found to be one of the effective inhibitors of P-glycoprotein (P-gp) [28], which can limit the bioavailability and ultimately their therapeutic efficacies.

\section{Conclusions}

The data presented in this study give a benchmark to advance the investigation of more derivatives in order to revamp the pharmacokinetic variables while maintaining both potency and metabolic constancy. The study also provides a simple and reproducible RP-HPLC method for determination of chalcones in plasma which can be opted in resource limiting settings.

\section{Limitations}

The present study focussed only on pharmacokinetic analysis of these chalcone derivatives. However, pharmacokinetic data supported by a parallel analysis of efficacy of malaria parasites in vivo would be more conclusive. Additionally, the use of rabbits for pharmacokinetic data is not as much reliable and replaceable compared to clinical pharmacokinetic studies.

\section{Abbreviations}

ABC: ATP binding cassette; AUC: Area under the total plasma concentrationtime curve; $C_{\text {max }}$ : Peak plasma concentration; CL: Plasma clearance; CPCSEA: Committee for the Purpose of Control and Supervision of Experiments on Animals; IP: Intraperitoneal; NMR: Nuclear magnetic resonance; OECD GLP: Organisation for Economic Co-operation and Development, Good Laboratory Practice; RP-HPLC: Reverse phase-high performance liquid chromatography; $t_{\max }$ : Time to reach the peak plasma concentration; $t_{1 / 2}$ : Elimination half-life; $V_{d}$ : volume of distribution.

\section{Supplementary Information}

The online version contains supplementary material available at https://doi. org/10.1186/s13104-021-05684-8.

Additional file 1. NMR characterization of chalcone derivatives.

Additional file 2: Figure S1. Calibration curve for chalcone derivative 1 (a), 2 (b), and 3(c).

\section{Acknowledgements}

Authors are thankful to Indian Council of Medical Research (ICMR), New Delhi, India for supporting Junior and Senior research fellowship to Shweta Sinha, reference no. 3/1/3/JRF-2012 HRD(80577). And also, we acknowledge Prof. Dr. Nikolay Vassilev, Bulgarian NMR Centre, Institute of Organic Chemistry with Centre of Phytochemistry, Bulgarian Academy of sciences, Bulgaria, SAIFChandigarh facility and DST, New Delhi, India for providing NMR facility.

\section{Authors' contributions}

SS, RS, BM, AP designed the study. SS and AP performed experiments and analysis. DIB contributed reagents and materials. SS drafted the manuscript. $\mathrm{RS}, \mathrm{BM}$, and AS helped in the reviewing, and editing of the manuscript. All authors read and approved the final manuscript.

\section{Funding}

This research did not receive any specific grant from funding agencies in the public, commercial, or not-for-profit sectors.

\section{Availability of data and materials}

All data generated or analysed during this study are included in this published article [and its additional files]. 


\section{Declarations}

\section{Ethical approval and consent to participate}

The ethical approval was taken from the Institutional Animal Ethics Committee, Postgraduate Institute of Medical Education and Research, Chandigarh, Reference No. 69/IAEC/418 as per the Committee for the Purpose of Control and Supervision of Experiments on Animals (CPCSEA) guidelines.

\section{Consent for publication}

Not applicable.

\section{Competing interests}

The authors declare that they have no competing interests.

\section{Author details}

'Department of Medical Parasitology, Post Graduate Institute of Medical Education and Research, Chandigarh 160012, India. ${ }^{2}$ Department of Pharmacology, Post Graduate Institute of Medical Education and Research, Chandigarh, India. ${ }^{3}$ Department of Obstetrics \& Gynecology, Government Medical College \& Hospital Sector 32, Chandigarh, India. Institute of Organic Chemistry With Centre of Phytochemistry, Bulgarian Academy of Sciences, Sofia, Bulgaria.

Received: 13 April 2021 Accepted: 5 July 2021

Published online: 08 July 2021

\section{References}

1. WHO. World Malaria Report. Geneva, Switzerland; 2019. https://www. whoint/publicationsdetail/world-malaria-report-2019.

2. Fairhurst RM, Dondorp AM. Artemisinin-resistant Plasmodium falciparum malaria. Microbiol Spectr. 2016. https://doi.org/10.1128/microbiolspec. El10-0013-2016.

3. Burrows JN, Burlot E, Campo B, Cherbuin S, Jeanneret S, Leroy D, Spangenberg T, Waterson D, Wells TN, Willis P. Antimalarial drug discoverythe path towards eradication. Parasitology. 2014;141(1):128-39.

4. Sahu NK, Balbhadra SS, Choudhary J, Kohli DV. Exploring pharmacological significance of chalcone scaffold: a review. Curr Med Chem. 2012;19:209-25.

5. Dhar DN. The chemistry of chalcones and related compounds. New York: Wiley; 1981.

6. Burlando B, Verotta L, Cornara L, Bottini-Massa E. Herbal principles in cosmetics: properties and mechanisms of action. Boca Raton: CRC Press; 2010.

7. Li R, Kenyon GL, Cohen FE, Chen X, Gong B, Dominguez JN, Davidson E, Kurzban G, Miller RE, Nuzum EO. In vitro antimalarial activity of chalcones and their derivatives. J Med Chem. 1995;38(26):5031-7.

8. Ballesteros JF, Sanz MJ, Ubeda A, Miranda MA, Iborra S, Payá M, Alcaraz MJ. Synthesis and pharmacological evaluation of 2'-hydroxychalcones and flavones as inhibitors of inflammatory mediators generation. J Med Chem. 1995;38:2794-7.

9. Dimmock JR, Kandepu NM, Hetherington M, Quail JW, Pugazhenthi U, Sudom AM, Chamankhan M, Rose P, Pass E, Allen TM, et al. Cytotoxic activities of Mannich bases of chalcones and related compounds. J Med Chem. 1998:41:1014-26.

10. Yit CC, Das NP. Cytotoxic effect of butein on human colon adenocarcinoma cell proliferation. Cancer Lett. 1994;82:65-72.

11. Wattenberg LW, Coccia JB, Galhaith AR. Inhibition of carcinogen-induced pulmonary and mammary carcinogenesis by chalcone administered after carcinogen exposure. Cancer Lett. 1994;83:165-9.
12. Dinkova-Kostova AT, Abeygunawardana C, Talalay P. Chemoprotective properties of phenylpropenoids, bis(benzylidene) cycloalkanones, and related Michael reaction acceptors: correlation of potencies as phase 2 enzyme inducers and radical scavengers. J Med Chem. 1998;41:5287-96.

13. Bois F, Boumendjel A, Mariotte AM, Conseil G, Di Petro A. Synthesis and biological activity of 4-alkoxy chalcones: potential hydrophobic modulators of P-glycoprotein-mediated multidrug resistance. Bioorg Med Chem. 1999;7:2691-5

14. Go ML, Wu X, Liu XL. Chalcones: an update on cytotoxic and chemoprotective properties. Curr Med Chem. 2005;12:481-99.

15. Sinha S, Batovska DI, Medhi B, Radotra BD, Bhalla A, Markova N, Sehgal R. In vitro anti-malarial efficacy of chalcones: cytotoxicity profile, mechanism of action and their effect on erythrocytes. Malar J. 2019;18(1):421.

16. Sinha S, Radotra BD, Medhi B, Batovska DI, Markova N, Sehgal R. Ultrastructural alterations in Plasmodium falciparum induced by chalcone derivatives. BMC Res Notes. 2020;13(1):290

17. Paudel A, Panthee S, Urai M, Hamamoto H, Ohwada T, Sekimizu K. Pharmacokinetic parameters explain the therapeutic activity of antimicrobial agents in a silkworm infection model. Sci Rep. 2018;8(1):1578.

18. Barnard R, Gurevich KG. In vitro bioassay as a predictor of in vivo response. Theor Biol Med Model. 2005;2:3.

19. Naik KM, Nandibewoor ST. Highly sensitive analysis of the chalcone in human plasma and urine by RP-High-performance Liquid Chromatography. Asian J Pharm Clin Res. 2011;4(1):105-7.

20. Gibaldi M, Perrier D. Pharmacokinetics. 2nd ed. New York: Marcel Dekker Inc.; 1982.

21. Gutteridge CE, Thota DS, Curtis SM, Kozar MP, Li Q, Xie L, Zhang J, Melendez V, Asher CO, Luong TT, et al. In vitro biotransformation, in vivo efficacy and pharmacokinetics of antimalarial chalcones. Pharmacology. 2011;87(1-2):96-104.

22. Okoniewska K, Konieczny MT, Lemke K, Grabowski T. Pharmacokinetic studies of oxathio-heterocycle fused chalcones. Eur J Drug Metab Pharmacokinet. 2017;1:49-58

23. Nwafor SV, Akah PA, Okoli CO, Onyirioha AC, Nworu CS. Interaction between chloroquine sulphate and aqueous extract of Azadirachta indica A. Juss (Meliaceae) in rabbits. Acta Pharm. 2003;53(4):305-11.

24. Moore BR, Page-Sharp M, Stoney JR, llett KF, Jago JD, Batty KT. Pharmacokinetics, pharmacodynamics, and allometric scaling of chloroquine in a murine malaria model. Antimicrob Agents Chemother. 2011:55(8):3899-907.

25. Harvey SC, Withrow CD. Basic pharmacokinetics. In: Gennaro AR, editor. Remington's pharmaceutical sciences. 8th ed. Mack Publishing Company, Easton; 1990. pp. 725-45.

26. Tadigoppula N, Korthikunta V, Gupta S, Kancharla P, Khaliq T, Soni A, Srivastava RK, Srivastava K, Puri SK, Raju KS, et al. Synthesis and insight into the structure-activity relationships of chalcones as antimalarial agents. J Med Chem. 2013;56(1):31-45.

27. Qiao H, Zhang X, Wang T, Liang L, Chang W, Xia H. Pharmacokinetics, biodistribution and bioavailability of isoliquiritigenin after intravenous and oral administration. Pharm Biol. 2014;52(2):228-36.

28. Liu XL, Tee HW, Go ML. Functionalized chalcones as selective inhibitors of P-glycoprotein and breast cancer resistance protein. Bioorg Med Chem. 2008;16(1):171-80.

\section{Publisher's Note}

Springer Nature remains neutral with regard to jurisdictional claims in published maps and institutional affiliations. 